\title{
Effects of Nylon Microplastic on Feeding, Lipid Accumulation, and Moulting in a Coldwater Copepod
}

\author{
Matthew Cole, ${ }^{*}, \oplus$ Rachel Coppock, ${ }^{\dagger, \dagger}$ Penelope K. Lindeque, ${ }^{* \dagger}$ Dag Altin, ${ }^{\S}$ Sarah Reed, $\|$ \\ David W. Pond, ${ }^{\|, \perp}$ Lisbet Sørensen, ${ }^{\#}$ Tamara S. Galloway, ${ }^{\ddagger}$ and Andy M. Booth ${ }^{\#}$ \\ ${ }^{\dagger}$ Marine Ecology and Biodiversity Group, Plymouth Marine Laboratory, Plymouth PL1 3DH, United Kingdom \\ ${ }^{\ddagger}$ College of Life and Environmental Sciences: Biosciences, University of Exeter, Exeter EX4 4QD, United Kingdom \\ ${ }^{\S}$ BioTrix, Trondheim NO-7022, Norway \\ "Scottish Association of Marine Science, Scottish Marine Institute, Oban PA37 1QA, United Kingdom \\ ${ }^{\perp}$ Institute of Aquaculture, University of Stirling, Stirling FK9 4LA, United Kingdom

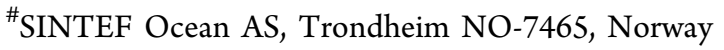 \\ Supporting Information
}

\begin{abstract}
Microplastic debris is a pervasive environmental contaminant that has the potential to impact the health of biota, although its modes of action remain somewhat unclear. The current study tested the hypothesis that exposure to fibrous and particulate microplastics would alter feeding, impacting on lipid accumulation, and normal development (e.g., growth, moulting) in an ecologically important coldwater copepod Calanus finmarchicus. Preadult copepods were incubated in seawater containing a mixed assemblage of cultured microalgae (control), with the addition of $\sim 50$ microplastics $\mathrm{mL}^{-1}$ of nylon microplastic granules $(10-30$ $\mu \mathrm{m})$ or fibers $(10 \times 30 \mu \mathrm{m})$, which are similar in shape and

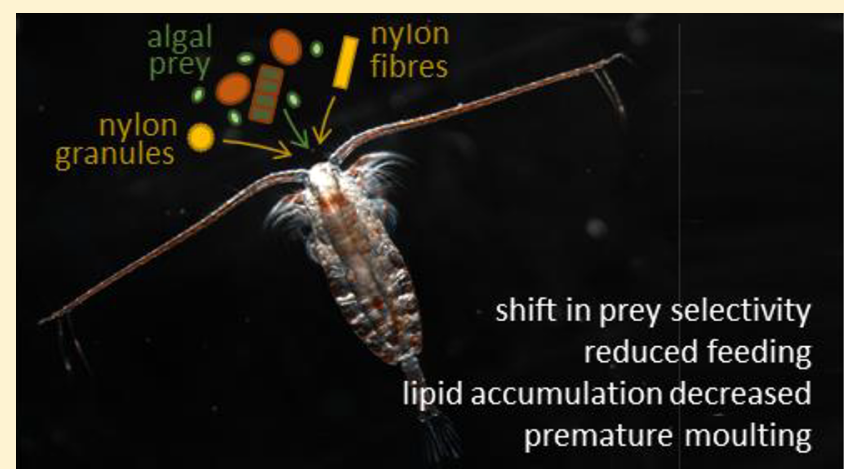
size to the microalgal prey. The additive chemical profiles showed the presence of stabilizers, lubricants, monomer residues, and byproducts. Prey selectivity was significantly altered in copepods exposed to nylon fibers (ANOVA, $P<0.01$ ) resulting in a nonsignificant $40 \%$ decrease in algal ingestion rates (ANOVA, $P=0.07$ ), and copepods exposed to nylon granules showed nonsignificant lipid accumulation (ANOVA, $P=0.62$ ). Both microplastics triggered premature moulting in juvenile copepods (Bernoulli GLM, $P<0.01$ ). Our results emphasize that the shape and chemical profile of a microplastic can influence its bioavailability and toxicity, drawing attention to the importance of using environmentally relevant microplastics and chemically profiling plastics used in toxicity testing.
\end{abstract}

\section{INTRODUCTION}

Microplastics $(1 \mu \mathrm{m}$ to $1 \mathrm{~mm})$ are a pervasive and persistent environmental contaminant, impinging on freshwater, terrestrial, and marine ecosystems across the globe. ${ }^{1,2}$ These synthetic particulates and fibers are either directly manufactured (e.g., exfoliates in personal care products), or derive from fragmentation of larger plastic debris. ${ }^{3,4}$ It is conservatively estimated that over $4.75 \times 10^{12}$ plastic particles (in the size range of $0.3-4.5 \mathrm{~mm}$ ) are floating in the global ocean. ${ }^{5}$ As complete mineralization of plastic debris is estimated to range from tens to hundreds of years, and with plastic inputs expected to rise for the foreseeable future, marine microplastic concentrations are likely to increase. ${ }^{6,7}$ Owing to their small size, microplastics can be directly or indirectly (i.e., via trophic interactions) ingested by a range of marine organisms across trophic levels, including zooplankton, ${ }^{8}$ shellfish, ${ }^{9}$ fish, ${ }^{10,11}$ and megafauna. ${ }^{12,13}$ Microplastics contain additives, plasticizers, and monomers (e.g., bisphenol A, polybrominated diphenyl ethers) incorporated during their manufacture to provide a wide range of functions including as emollients, stabilizers, and flame retardants. ${ }^{14}$ Furthermore, they may carry persistent organic pollutants (POPs), metals, and pathogens that adsorb or adhere to their surface in the marine environment. ${ }^{15,16}$ Where equilibrium has not been reached (i.e., there is a chemical gradient), there is evidence that POPs and metals (e.g., copper, zinc) can transfer from microplastics into biota potentially enhancing their toxicity. ${ }^{17,18}$ Laboratory testing has highlighted the negative impacts microplastic ingestion can have on marine organisms, including zooplankton, mussels, oysters, crustaceans, and fish, with effects including reduced feeding, fecundity, growth, and survival. ${ }^{19-24}$ These effects can cascade through levels of biological organization, resulting in

Received: March 27, 2019

Revised: $\quad$ May 18, 2019

Accepted: May 20, 2019

Published: May 24, 2019 
impacts on the ecological functionality of keystone species (e.g., bioturbation, nutrient cycling). ${ }^{25}$

Copepods are an abundant class of marine zooplankton that provide an essential trophic link between primary producers and secondary consumers, and contribute to ecological processes such as marine nutrient cycling. ${ }^{26}$ Laboratory exposures have demonstrated the capacity for a range of pelagic and benthic copepods, including Acartia spp., Calanus spp, Centropages spp., Limnocalanus spp., Temora spp., and Tigriopus spp., to ingest polystyrene microplastic beads and fragments. ${ }^{27-30}$ Furthermore, wild copepods sampled from the South China Sea ${ }^{31}$ and Northeast Pacific Ocean ${ }^{32}$ have been shown to ingest microplastic fibers and particulates in the natural environment. Exposure studies have highlighted that polystyrene microspheres can negatively affect copepod feeding and health. Exposed to a monoalgal diet and polystyrene beads $\left(20 \mu \mathrm{m} ; 65\right.$ microplastics $\left.\mathrm{mL}^{-1}\right)$, the temperate calanoid copepod Calanus helgolandicus showed significant reductions in their dietary intake of carbon owing to a shift in feeding, with a preference for smaller, less nutritious algae. $^{22}$ After 3 days exposure, Cole et al. ${ }^{22}$ observed microplastic exposed copepods produced significantly smaller eggs with reduced hatching success, which was attributed to reduced energetic intake. There is relatively little data currently available to determine whether microplastics with different physical properties (e.g., shape, size, density) ${ }^{33}$ will exhibit altered bioavailability or toxicity, and there are few published microplastic exposure studies focused on early life stages. Incorporation of microplastics more representative of those found in the environment (i.e., irregularly shaped, fibers) and consideration of impacts on early life stages have been encouraged within the scientific community. ${ }^{34,35}$

In this study, we investigate the impact of fibrous and particulate microplastic exposure on feeding, lipid accumulation, growth, and moulting in preadult Calanus finmarchicus, a boreal (coldwater) copepod that is widely distributed in the northern hemisphere and the dominant mesozooplankton species in the North Sea and Norwegian Sea. ${ }^{36}$ The energetic reserve of $C$. finmarchicus takes the form of a large oil sac, comprising wax esters with long-chain fatty acids and fatty alcohols, built-up during their juvenile life stages in periods of high food availability. ${ }^{37,38}$ These lipid stores make $C$. finmarchicus nutritionally valuable to higher-trophic organisms (e.g., fish, whales), and facilitate "diapause", whereby the copepods descend to deeper waters and enter a state of dormancy over winter. ${ }^{39,40}$ We hypothesized that reductions in algal feeding stemming from microplastic exposure would result in reduced lipid accumulation in developing $C$. finmarchicus with consequences for the normal development of the copepod. In our experiments, cohorts of preadult $C$. finmarchicus (copepodite stage, CV) were exposed to mixed algal assemblages with the addition of either nylon microplastic fibers or granules at a concentration of 50 microplastics $\mathrm{mL}^{-1}$ for 6 days, with sublethal end points including: algal ingestion rates, growth, lipid mass and profiles, and moulting. Our results provide evidence of the risks fibrous and particulate microplastics pose to the energetics and development of a keystone species.

\section{MATERIALS AND METHODS}

Copepods and Microalgae. Juvenile Calanus finmarchicus (CV) were subsampled from copepod cultures maintained at the Norwegian University of Science and Technology
(NTNU). Copepods were fed a mixed assemblage of three microalgal species of different size and shape (Supporting Information, SI, Figure S1), which are part of the natural diet of Calanus sp.: (i) the chlorophyte Dunaliella tertiolecta $(9 \times 13$ $\mu \mathrm{m})$; (ii) the chain-forming diatom Thalassiosira rotula $(19 \times$ $24 \mu \mathrm{m})$; and (iii) the dinoflagellate Scripsiella trochoidea $(29 \times$ $34 \mu \mathrm{m}$ ). Algae were cultured with $\mathrm{F} / 2$ media, with addition of silica for T. rotula, and maintained at $18{ }^{\circ} \mathrm{C}$ at a $16: 8$ light/dark cycle. Copepods were fed a nonlimiting concentration of microalgae, comprising $\sim 200$ cells $\mathrm{mL}^{-1}$ of $D$. tertiolecta, $\sim 50$ cell $\mathrm{mL}^{-1}$ of $T$. rotula, and $\sim 15$ cells $\mathrm{mL}^{-1}$ of $S$. trochoidea. $D$. tertiolecta were quantified using a Coulter Counter (Beckman Multisizer 3), while T. rotula and S. trochoidea were quantified using a Sedgewick rafter chamber. C. finmarchicus were acclimated to their algal prey for $48 \mathrm{~h}$ prior to experiments. The carbon biomass of algal prey was estimated using a literature derived conversion factor of $5 \mathrm{~nL}$ biovolume $\approx 1 \mu \mathrm{g}$ C. ${ }^{41}$ To calculate algal biovolume, microalgae were imaged under an inverted microscope (Nikon TE2000S), cellular dimensions determined using ImageJ, and the formulas for a volume of an ellipsoid (D. tertiolecta and S. trochoidea) or cylinder ( $T$. rotula) applied.

Microplastics. Nylon fibers $(10 \times 30 \mu \mathrm{m})$, of a similar shape and size as the chain-forming microalgae $T$. rotula, were prepared by sectioning polyamide nylon-6,6 polyfilament line (Goodfellow; AM325705) per the method of Cole (2016). ${ }^{42}$ In brief, the polyfilament line was wrapped continuously around a custom spool, embedded in TissueTek cryogenic solution, and then sectioned at $30 \mu \mathrm{m}$ intervals using a cryogenic microtome (LEICA CM1950). Nylon granules (10$30 \mu \mathrm{m}$ ), of a similar shape and size distribution as the unicellular microalgae $D$. tertiolecta and $S$. trochoidea, were prepared by size fractionating polyamide nylon-6 powder (Goodfellow; AM306010) with $30 \mu \mathrm{m}$ nylon mesh and $10 \mu \mathrm{m}$ polycarbonate membrane filters. Prior to use, microplastics were rinsed with ethanol and copious amounts of ultrapure water, suspended in ultrapure water and quantified using a Sedgewick rafter chamber. For imaging purposes, a subsample of the fibrous and granular microplastics were dyed with Nile $\operatorname{Red}\left(500 \mu \mathrm{g} \mathrm{mL}^{-1}\right)$.

Chemical Profiling. To ascertain what compounds (e.g., monomers, additives) were present in the microplastics, samples of fibers $(\sim 20 \mathrm{mg})$ and granules $(\sim 50 \mathrm{mg})$ were extracted using either $4 \mathrm{~mL}$ of dichloromethane (DCM, Rathburn; $n=3$ ) or $4 \mathrm{~mL}$ of ethyl acetate (EtOAc, Fluka; $n=$ 3 ). Solvent was added to each sample and then the sample sonicated for $30 \mathrm{~min}$ (Bandelin Sonorex Super RK $510 \mathrm{H}$ ultrasonication bath, $640 \mathrm{~W}, 35 \mathrm{kHz}$ ) at either room temperature $(\mathrm{DCM})$ or $65{ }^{\circ} \mathrm{C}$ (EtOAc). The solvent extract was filtered through a pipette packed with Bilson cotton and a small amount $(\sim 50 \mathrm{mg})$ of anhydrous $\mathrm{Na}_{2} \mathrm{SO}_{4}$ to remove particulates, and then concentrated by solvent evaporation (40 ${ }^{\circ} \mathrm{C}$ under a gentle flow of $\mathrm{N}_{2}$ ) to an approximate volume of $500 \mu \mathrm{L}$ prior to analysis by GC-MS (Agilent 7890A GC equipped with an Agilent 5975C Mass Selective Detector). Here, the inlet was set to $250{ }^{\circ} \mathrm{C}$, the transfer line to $300{ }^{\circ} \mathrm{C}$, the ion source to $230{ }^{\circ} \mathrm{C}$ and the quadrupole to $150{ }^{\circ} \mathrm{C}$. The carrier gas was helium, at a constant flow of $1.1 \mathrm{~mL} / \mathrm{min}$. One $\mu \mathrm{L}$ of sample was injected by pulsed splitless injection (Agilent DB5-MS ultrainert GC column; $30 \mathrm{~m}, 0.25 \mu \mathrm{m}$ film thickness, $0.25 \mathrm{~mm}$ internal diameter). The GC oven was held at $40{ }^{\circ} \mathrm{C}$ ( $2 \mathrm{~min}$ ), ramped by $6{ }^{\circ} \mathrm{C} \mathrm{min}^{-1}$ to $320{ }^{\circ} \mathrm{C}$ (20 min hold). Mass spectra were recorded after $12 \mathrm{~min}$ of hold time (50-500 
$m / z)$. Chromatograms and mass spectra were recorded using Chemstation software, investigated in Masshunter Qualitative Navigator B.08.00, further processed using Masshunter Unknowns Analysis ("Unknowns") followed by export to csv format using Python and data processed in R. After initial inspection of chromatograms, peaks were deconvoluted using Unknowns algorithms and best hits from the NIST 2017 library were extracted. Compounds were filtered based on observed presence in at least 3 of the 6 total replicates and $>80 \%$ match to NIST 2017 library mass spectra.

Exposure. Treatments comprised: (i) controls, (ii) nylon fibers, and (iii) nylon granules. Exposure media consisted of $0.22 \mu \mathrm{m}$ filtered natural seawater containing mixed algal prey and $20 \mathrm{~mL}$ of Guillard's F/2 media to ensure water remained nutrient replete, plus 50 microplastics $\mathrm{mL}^{-1}$ of nylon fibers or granules as applicable. Stocks were prepared daily, thoroughly mixed with a perforated plunger, and then carefully poured into $1 \mathrm{~L}$ glass bottles $(n=10$ per treatment). Ten preadult copepods (copepodite stage $\mathrm{CV}$ ) were added to each bottle, and exposure media used to fill all bottles to the brim (total volume $1150 \mathrm{~mL}$ ), thereby eliminating air bubbles. To account for the natural growth of the algae (see Algal ingestion rates), exposure media in $500 \mathrm{~mL}$ bottles $(n=5)$ was also incubated without copepods on Day 3-4. Bottles were secured to a rotating plankton wheel $(<5 \mathrm{rpm})$ submerged in a water bath for temperature stability, and the setup maintained at $8.7 \pm 0.1$ ${ }^{\circ} \mathrm{C}$ in the dark for a total of 6 days. Water changes were conducted daily by gently pouring the contents of each bottle through a partially submerged $500 \mu \mathrm{m}$ mesh to isolate copepods; on Day 3-4 media was preserved for calculation of algal ingestion rates. The developmental stage of each copepod was noted (see Moulting), and then the specimens transferred to fresh media. Any individuals damaged during water changes were removed and if experimental cohorts were reduced by $>50 \%$ the replicate was rejected. At the end of the exposure, copepods were anaesthetised using FinQuel (MS222), and then photographed under a stereo microscope (Leica MZAPO/Nikon DigitalSight Fi1-U2). Individual copepods were transferred to a cryovial, snap-frozen in liquid nitrogen and subsequently stored at $-80{ }^{\circ} \mathrm{C}$ prior to lipid analysis.

Microplastic Uptake. To verify that juvenile $C$. finmarchicus had the capacity to ingest microplastics, we conducted a $2 \mathrm{~h}$ exposure (per the experimental protocol described above) using nylon fibers and granules dyed with Nile Red (100 microplastics $\mathrm{mL}^{-1}$ ). Following the exposure, copepods and their faecal pellets were isolated using a $63 \mu \mathrm{m}$ mesh, transferred to a clean glass Petri dish, and subsequently visualized and photographed under a stereo microscope (Leica MZAPO/Nikon DigitalSight Fi1-U2) equipped with a stereofluorescence module (Leica "green" fluorescent filter; excitation 546/10 nm, dichroic splitter $565 \mathrm{~nm}$ and emission OG590).

Algal Ingestion Rates. Feeding rates (i.e., algal ingestion rates) were assessed midway through the exposure (Day 3-4). At $T_{0}$ (Day 3), $200 \mathrm{~mL}$ subsamples of algal stocks were collected and preserved with $2 \%$ Lugols solution $(n=5$ per treatment). After $24 \mathrm{~h}$ (Day 4), $200 \mathrm{~mL}$ subsamples were taken from all bottles (including algal controls without predation), and fixed with $2 \%$ Lugols. Preserved samples were maintained in amber glass bottles prior to analysis to prevent degradation. Microalgae were quantified using the Utermöhl technique (BSEN15204:2006). In brief, samples were settled in $100 \mathrm{~mL}$
Utermöhl chambers for $48 \mathrm{~h}$, samples viewed under inverted microscope (Olympus IMT2) and cells systematically enumerated. Cell concentrations and mean carbon biomass of the microalgae were subsequently used to calculate algal ingestion rates $\left(\mu \mathrm{g} \mathrm{C}\right.$ individual ${ }^{-1}$ day $\left.^{-1}\right)$ per the equation of Frost. $^{43}$

Prosome Length. The prosome length $(\mu \mathrm{m})$ of copepods was ascertained for copepods subsampled from initial stocks (Day $0, n=25$ ) and juvenile, female and male copepods at the end of the 6-day exposure. In all cases, individual copepods were anaesthetised and photographed under a stereo microscope (Leica MZAPO/Nikon DigitalSight Fi1-U2), and prosome length measured using ImageJ software.

Total Lipid Mass and Lipid Profiles. Copepod lipids were extracted by adapting the protocol of Folch et al., ${ }^{44}$ adding $500 \mu \mathrm{L}$ of chloroform-methanol $(2: 1 \mathrm{v} / \mathrm{v})$ and then placing the sample in a $-20{ }^{\circ} \mathrm{C}$ freezer for $4 \mathrm{~h}$. Next, a phase separation of nonpolar lipids and polar organics/compounds was undertaken by adding $130 \mu \mathrm{L}$ potassium chloride $(0.88 \%$ $\mathrm{w} / \mathrm{w})$, and then vortexing (12-16 rpm), and centrifuging (2.5 min, $2500 \mathrm{rpm}$ ) the sample. A glass-steel pipette was used to carefully extract and transfer the bottom phase (containing nonpolar lipids) to a preweighed glass vial. The solvent was gently evaporated using nitrogen gas, and the sample desiccated under vacuum in the dark for $30 \mathrm{~min}$. Finally, the vial was weighed on a mass balance to ascertain the total lipid mass (mg). To assess the lipid content of the microalgae, 1-2 $\mathrm{mL}$ of microalgae were filtered through a GFF; filters were placed in $7 \mathrm{~mL}$ glass vials, the lipids extracted using $5 \mathrm{~mL}$ of chloroform-methanol $(2: 1 \mathrm{v} / \mathrm{v})$, and then processed as above. Prior to lipid profiling, $250 \mu \mathrm{L}$ of chloroform was added to each vial, and samples stored at $-20^{\circ} \mathrm{C}$. For determination of lipid profiles, internal standards (23:0, fatty acid and 19:0 fatty alcohol) were added to the total lipid samples prior to methylation in $1 \%$ methanol for $16 \mathrm{~h}$ at $50{ }^{\circ} \mathrm{C}$. Fatty acid methyl esters and free fatty alcohols were purified using High Performance Thin Layer Chromatography (HPTLC) and analyzed by gas chromatography using a Thermo Trace 2000 GC equipped with a Resteck Stabilwax column.

Moulting. Every $24 \mathrm{~h}$ the developmental stage of copepods was determined, based upon the morphological characteristics of each copepod (SI Figure S2). For adult copepods, their sex was determined at the end of the exposure period through morphological assessment of anaesthetised specimens.

Statistical Analyses. Statistical analysis was conducted using R statistical software V 1.0.136. ${ }^{45}$ Data were tested for normality using a Shapiro-Wilk test and homogeneity of variance was visually inspected to satisfy apriori parametric requisites. An ANOVA with posthoc Tukey tests was used to compare biological data including algal ingestion rates, prosome length, and lipid mass. A General Linear Model (GLM) was used to compare fatty acid and alcohol data. Moulting data were assembled into binary format ("Moulted = 1 ", "Not-moulted $=0$ "), and a Bernoulli GLM used to assess the probability of copepod moulting for each treatment, with homogeneity among replicates determined using "binomial" family and "logit" link functions. Model assumptions were validated by extracting deviance residuals and examining their distribution. Data are presented as mean \pm standard error, with statistical significance assigned where $P<0.05$. 


\section{RESULTS}

Microplastic Uptake. Following a $2 \mathrm{~h}$ exposure, nylon fibers and granules were visualized in the intestinal tracts and faecal pellets of the juvenile copepods, confirming uptake and egestion (Figure 1).
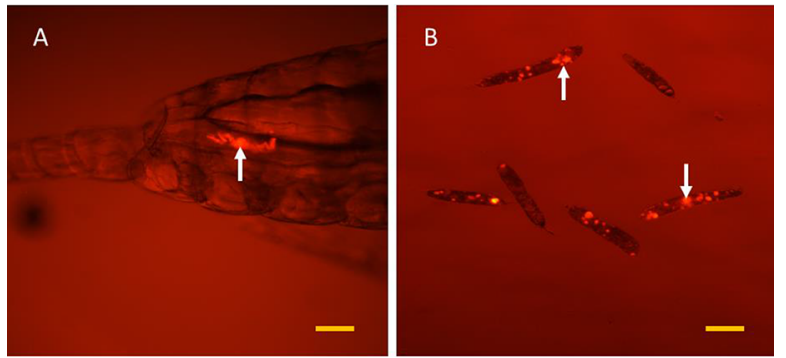

Figure 1. Ingestion and egestion of microplastics by juvenile Calanus finmarchicus: (A) nylon fibers $(10 \times 30 \mu \mathrm{m})$ in the intestinal tract; (B) nylon granules $(10-30 \mu \mathrm{m})$ in the faecal pellets. Nylon microplastics were fluorescently dyed with Nile Red and visualized under stereo microscope (Leica MZAPO/Nikon DigitalSight Fi1-U2) equipped with a Leica "green" fluorescent filter (excitation 546/10 $\mathrm{nm}$, dichroic splitter $565 \mathrm{~nm}$ and emission OG590). Yellow bars: 100 $\mu \mathrm{m}$.

Additive Chemical Profiling. A range of monomers, manufacturing byproducts and additives, including lubricants, stabilizers and antimicrobials, were tentatively identified (based on $>85 \%$ match) in the nylon fibers (SI Table S1) and granules (SI Table S2). Four compounds were common to both plastics: the monomer caprolactam (hexano-6-lactam); the lubricants cyclomethicone 6 (dodecamethylcyclohexasiloxane) and cyclomethicone 5 (decamethylcyclopentasiloxane); and $1 \mathrm{H}$-tetrazol-5-amine. The UV stabilizer benzophenone was identified in nylon fibers.

Algal Ingestion Rates. Average microalgal dimensions (SI Table S3) were used to calculate mean carbon biomass per cell values of $0.98 \mathrm{ng} \mathrm{C}$ for D. tertiolecta, $1.66 \mathrm{ng} \mathrm{C}$ for T. rotula, and $25.2 \mathrm{ng} \mathrm{C}$ for $S$. trochoidea. Mean microplastic concentrations in aqueous media were 46.6 fibers and 53.4 granules $\mathrm{mL}^{-1}$; mean ingestion rates for microplastics were $\sim 1700$ fibers copepod ${ }^{-1} \mathrm{~d}^{-1}$ and $\sim 5700$ granules copepod $^{-1}$ $\mathrm{d}^{-1}$. Copepods exposed to both fibers and granules showed a slight (nonsignificant) increase in algal ingestion rates for $D$. tertiolecta (ANOVA, $P=0.30$; Figure 2A). Copepods exposed to nylon fibers showed significant reductions in algal ingestion rates for $T$. rotula and $S$. trochoidea (ANOVA, $P<0.01$; Figure 2B/C), whereas copepods exposed to nylon granules showed no differences in feeding rates for $T$. rotula (ANOVA, $P=$ 0.44 ) or $S$. trochoidea (ANOVA, $P=0.87$ ). Overall, copepods exposed to fibers showed an average $40 \%$ reduction in algal ingestion (ANOVA, $P=0.07$; Figure 2D). No difference in total algal ingestion rates were observed for copepods exposed to nylon granules (ANOVA, $P=0.88$ ).

Prosome Length. There was no significant difference in the prosome length of juvenile (ANOVA, $P=0.65$ ), female (ANOVA, $P=0.09$ ), or male (ANOVA, $P=0.58$ ) copepods exposed to either type of microplastic (SI Figure S3).

Total Lipid Mass and Lipid Profiles. The average lipid mass of juvenile copepods at the start of the experiment was $66.7 \pm 5.5 \mu \mathrm{g}$. Significant lipid accumulation was observed in juvenile copepods in the control and fiber treatments (ANOVA, $P<0.01$ ), but not the granule treatment
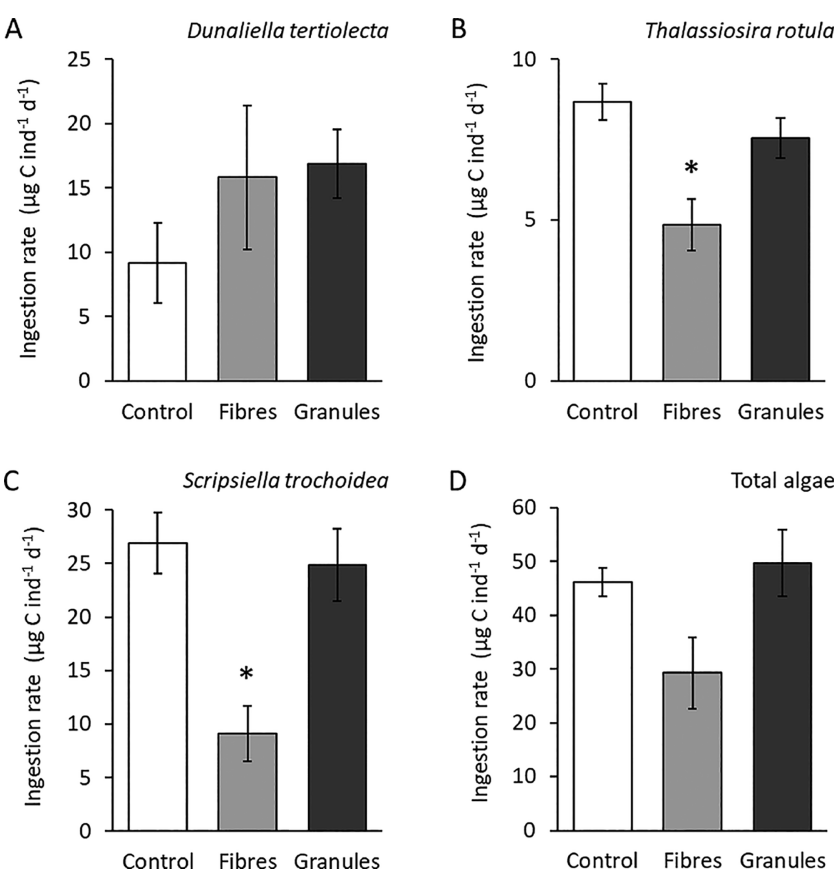

Figure 2. Juvenile Calanus finmarchicus ingestion rates ( $\mu \mathrm{g} \mathrm{C}$ individual $^{-1}$ day $^{-1}$ ) for: (A) D. tertiolecta; (B) T. rotula; (C) $S$. trochoidea; and (D) total algae. Results displayed as mean with standard error. $*$ denotes significant different from control $(P<0.05)$.

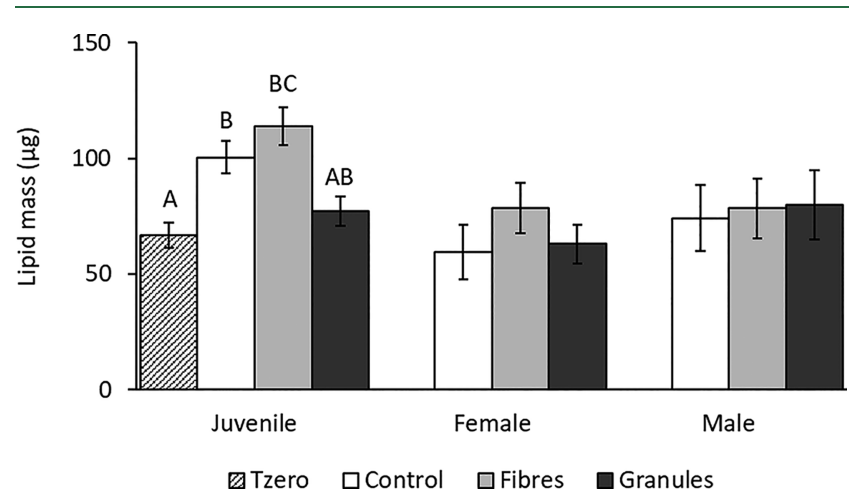

Figure 3. Impact of fibrous and particulate microplastics on lipid accumulation in C. finmarchicus. The lipid mass $(\mu \mathrm{g})$ of juvenile $(\mathrm{CV})$, female and male $C$. finmarchicus prior to the start of experiment $\left(T_{\text {zero }}\right.$; checked pattern) and following a 6-day exposure period. Treatments: control (white), nylon fibers (light gray), and nylon granules (dark gray). Letters show significant difference between treatments (ANOVA with posthoc Tukey).

(ANOVA, $P=0.63$; Figure 3 ). The average lipid content of juvenile copepods in the control treatment $(100.4 \pm 7.0 \mu \mathrm{g})$ exceeded that of copepods in the granule treatment (77.2 \pm $6.3 \mu \mathrm{g})$, however this difference was not statistically significant (ANOVA, $P=0.07$; Figure 3 ). Furthermore, no significant differences were observed in the lipid mass of female (ANOVA, $P=0.42$ ) or male (ANOVA, $P=0.96$ ) copepods. There was no significant difference in juvenile copepod fatty acid (GLM, control-fibers, $P=0.09$; GLM, control-granules $P$ $=0.34$; SI Figure S4) or fatty alcohol (GLM, control-fibers $P=$ 0.80 ; GLM, control-granules $P=0.90$; SI Figure S5) composition. For individual fatty acids and alcohols, the prevalence of palmitoleic acid $\left(16: 1\left(\mathrm{n}^{-7}\right)\right)$ and linoleic acid $\left(18: 2\left(\mathrm{n}^{-6}\right)\right)$ were significantly reduced in the fiber treatment (GLM, $P<0.05$ ), and the prevalence of palmityl alcohol 
(16:0) significantly reduced and arachidyl alcohol (20:1) significantly increased in the granule treatment (GLM, $P<$ $0.05)$.

Moulting. Across Days 0-4 there was no evidence of moulting in any treatment (Figure 4). The Bernoulli GLM

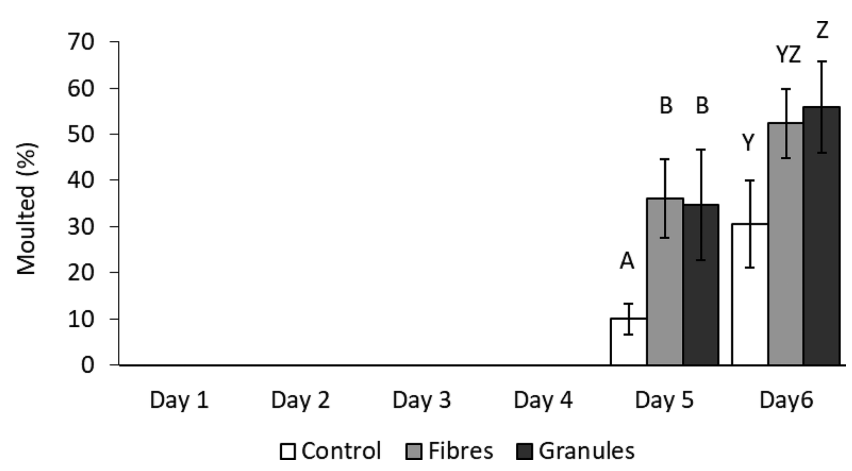

Figure 4. Impact of fibrous and particulate microplastics on moulting in C. finmarchicus. Percentage of copepods which moulted on each day of the exposure period. Treatments: control (white), nylon fibers (light gray), and nylon granules (dark gray). Letters denote significant difference (in moulting each day) between treatments $(P<0.05)$.

showed the "replicate" factor was not significantly different among treatments for Day $5(b=0.03, z=0.51, P=0.61)$ or Day $6(b=-0.07, z=-0.84, P=0.40)$ and was therefore excluded from further analyses. On Day 5, $9.0 \pm 3.2 \%$ of copepods had moulted in the control treatment, while a significantly greater proportion of copepods had moulted in the nylon fiber treatment $(36.1 \pm 8.6 \%$; Bernoulli GLM, $b=$ $1.47, z=0.5, P<0.01)$ and nylon granule treatments $(34.4 \pm$ 10.7\%; Bernoulli GLM, $b=1.42, z=0.51, P<0.01$; Figure 4). The proportion of copepods reaching adulthood increased between Days 5 and 6 for all treatments. On Day $630.6 \pm$ 9.5\% of controls had moulted, with a higher proportion of moults in copepods exposed to nylon fibers (52.3 $\pm 7.5 \%$; Bernoulli GLM, $b=0.86, z=1.84, P=0.07)$ and a statistically significant higher proportion of moults in copepods exposed to nylon granules (55.9 $\pm 9.9 \%$; Bernoulli GLM, $b=1.14, z=$ $0.49, P<0.05)$.

\section{DISCUSSION}

Our study reveals that microplastic exposure can impact upon prey selectivity, feeding, lipid accumulation, and moulting in a keystone marine organism. Microplastic shape influenced bioavailability and observed effects, with exposure to nylon fibers causing significant shifts in prey selectivity resulting in a $40 \%$ decrease in algal ingestion rates, and nylon granules negatively affecting lipid accumulation. We further observed that both microplastic types caused premature moulting, although the mechanism underpinning this developmental shift remains unclear. These results add to the growing evidence that at high concentrations, marine microplastics can significantly affect copepod feeding and health, with potential knock-on effects for marine food webs and ecological processes in which copepods play vital roles.

Uptake. Ingestion and egestion of both nylon microplastic fibers and granules was observed in juvenile C. finmarchicus. The capacity for copepods and other zooplankton to ingest spherical polystyrene beads under laboratory conditions has been widely demonstrated, ${ }^{34}$ and juvenile $(\mathrm{CV})$, female and male $C$. finmarchicus have been shown to readily ingest and egest polystyrene fragments $(<30 \mu \mathrm{m}$ diameter $) .^{30}$ Furthermore, irregularly shaped and fibrous microplastics have been identified in wild copepods sampled from the natural environment. ${ }^{31,32}$

Feeding. When exposed to the fibrous microplastics, juvenile $C$. finmarchicus demonstrated substantial shifts in feeding, with significantly reduced ingestion rates for the largest algae $T$. rotula $(19 \times 24 \mu \mathrm{m})$ and S. trochoidea $(29 \times 34$ $\mu \mathrm{m})$, contributing to a $40 \%$ decrease in ingested biomass compared with controls. A comparable shift in feeding selectivity was observed in the temperate copepod Calanus helgolandicus, in which exposure to $20 \mu \mathrm{m}$ polystyrene beads resulted in a preferential shift toward smaller algae, similarly resulting in a $40 \%$ reduction in ingested biomass. ${ }^{22}$ In mixed algal assemblages C. finmarchicus typically predate on larger, nutritionally valuable prey (e.g., diatoms, dinoflagellates, and ciliates) ${ }^{46,47}$ for which they display higher filtration rates and feeding efficiencies. ${ }^{48,49}$ This preference for larger algae is evident for copepods in the control and granule treatments, with $>50 \%$ of ingested biomass derived from $S$. trochoidea. However, for copepods exposed to fibers the majority of ingested biomass came from the smallest algae, D. tertiolecta ( 9 $\times 13 \mu \mathrm{m})$. This shift in prey selectivity would therefore suggest copepods are avoiding microalgae of similar shape (i.e., chainforming $D$. tertiolecta) and size (i.e., S. trochoidea) to the nylon fibers $(10 \times 30 \mu \mathrm{m})$. This hypothesis is further supported by our finding that fibers were ingested far less readily than granules. Why this is the case is currently unclear. Perhaps their elongated shape make fibers harder to capture, handle, and ingest, or, when consumed, fibers are more prone to causing physical damage owing to their sharp edges (Supporting Information, Figure S1); conversely, granules are relatively spherical in shape, and are likely handled similarly to naturally occurring particulates (e.g., pumice, wood, black carbon, and silt) to which copepods are well adapted. The risks microplastic fibers pose to biota is relatively underexplored, however exposure studies have identified that in the freshwater zooplankton Daphnia magna and Gammarus fossasrum ingestion of synthetic fibers resulted in early mortality ${ }^{50}$ and impaired feeding ${ }^{51}$ respectively.

Lipids. In juvenile C. finmarchicus (CV), approximately $40 \%$ of energy derived from their food goes toward the buildup of their lipid store. ${ }^{49}$ On the basis of the observed reduction in feeding in juvenile $C$. finmarchicus exposed to microplastic fibers and the shift to smaller, less nutritious algae, it was anticipated that the lipid mass of these copepods would be negatively affected; furthermore, we surmised that a shift in feeding may result in an altered lipid profile. Yet, there was no significant difference in the total lipid mass of juvenile, female, or male copepods at the end of the exposure period, nor were the lipid profiles of the juvenile copepods significantly altered. Given that a nonlimiting supply of food was provided to the copepods, it is plausible that even with a $40 \%$ reduction in ingested biomass that the juvenile $C$. finmarchicus still consumed sufficient energy to continue laying down their lipid reserves. Certainly, high latitude zooplankton can display a range of strategies to survive periods of low food availability, $^{52}$ and C. finmarchicus exhibit far greater starvation tolerance ( $>21$ days) than temperate species. ${ }^{39}$

We did observe that lipid accumulation was stymied in preadult copepods exposed to nylon granules. This was surprising given that nylon granules caused no impact on feeding rate. This intriguing result might be explained by the 
substantially higher ingestion rate for granules, as compared with fibers: high microplastic loads in the intestinal tract could limit assimilation efficiencies, as observed in the freshwater amphipod G. fossarum; ${ }^{53}$ alternatively, higher microplastic loads could lead to greater quantities of toxic additives or monomers permeating from the microplastic into tissues. ${ }^{51}$

Lipid mass is directly related to the depth at which copepods can successfully descend during diapause; smaller lipid reserves would result in overwintering at shallower depths leaving these copepods more prone to predation. ${ }^{54}$ There are also repercussions for the wider marine food web, as a reduced lipid content would make these copepods less nutritionally valuable as a food source for higher trophic organisms including commercially important fish species and megafauna. ${ }^{36}$

Moulting. Our study further identified that copepods exposed to nylon microplastics moulted significantly earlier than copepods in the control treatment. Juvenile $C$. finmarchicus have a flexible life history, where they can either enter diapause or moult into their adult life stage. Tarrant et al. $^{40}$ notes, "the factors that regulate this developmental plasticity are poorly understood", although lipid profiles, temperature, light, food availability, and endogenous clocks have all been mooted as contributing factors in diapause. ${ }^{55}$ Cultured C. finmarchicus do not initiate diapause, instead undergoing morphological changes, including gonad maturation, tooth formation, and apolysis (separation of the cuticle from the epidermis), prior to their terminal moult. ${ }^{56}$ Reduced feeding and stymied lipid accumulation may both have contributed to earlier moulting; however endocrine disruption might also have played a role. A transcriptomic evaluation of juvenile $C$. finmarchicus $(\mathrm{CV})$ has identified an array of genes linked to moulting, activated by an ecdysteroid hormone signaling cascade. ${ }^{40}$ A range of endocrine disrupting compounds have been shown to interfere with ecdysteroid pathways and affect moulting in crustacea; ${ }^{57}$ for example, estrogenic compounds have been shown to inhibit or delay moulting in the copepod Acartia tons $a^{58}$, while the pesticide emamectin benzoate has been demonstrated to cause premature moulting in American lobster, Homarus americanus. ${ }^{59}$ Chemical analysis revealed the nylon microplastics used in these exposures contain compounds that may cause toxicity or endocrine disruption-although it should be noted this analysis does not tell us which compounds, nor how much, could be expected to leach from the nylon either in seawater or the intestinal tract of a copepod. For example, the UVstabilizer benzophenone, identified in the nylon fibers, has been shown to increase DNA methylation and significantly reduce egg hatching success in the marine copepod Gladioferens pectinatus, ${ }^{60}$ and act as an oestradiol agonist in rats ${ }^{61}$ and fish. ${ }^{62,63}$ It is crucial to recognize that plastics are not an inert material, but a complex mixture of polymers containing a wide spectrum of compounds that have the potential to leach out. ${ }^{64}$ Given the capacity for these compounds to cause endocrine disruption or toxicity, it is crucial that chemical profiling of microplastics used in toxicity testing becomes more commonplace.

Environmental Relevance. In this exposure study we demonstrate that microplastics have the capacity to reduce feeding, stymie lipid accumulation, and trigger premature moulting in a boreal copepod. It should be noted that microplastic concentrations used in our exposure studies exceed those currently observed in the marine environment- although we would also highlight there is very little environmental data relating to concentrations of particles $10-30 \mu \mathrm{m}$ in size owing to the technical challenges of sampling, extracting and identifying plastic particles of this size and where data are available, it suggests the smaller the microplastics the higher the concentration becomes. ${ }^{65-68}$ While it is important the field of microplastics research shifts toward better understanding the risks environmentally relevant concentrations of microplastic pose to marine life, at this stage it remains essential to build a clearer picture of the modes of action by which microplastics can cause harm, identify relevant end points, and gauge the sensitivity of different life-stages and species. ${ }^{69}$ Such knowledge is key in establishing probable and no-effect thresholds for risk assessment. In this study, the use of preadult copepods highlights that microplastics can affect moulting, which will inform future experimental work. As our results demonstrate, the shape and chemical profile of a microplastic can influence bioavailability and toxicity, and we would therefore promote the call for future studies to better incorporate a greater diversity of environmentally relevant microplastics.

\section{ASSOCIATED CONTENT}

\section{Supporting Information}

The Supporting Information is available free of charge on the ACS Publications website at DOI: 10.1021/acs.est.9b01853.

Images of the microalgae, microplastics, and copepods; chemical data for the nylon fibers and granules; data relating to the size and shape of microalgae; and fatty acid and alcohol data for copepods in control, fiber, and granule treatments (PDF)

\section{AUTHOR INFORMATION}

\section{Corresponding Authors}

*Phone: +44(0)1752 633100; e-mail: mcol@pml.ac.uk. *Phone: +44(0)1752 633100; e-mail: pkw@pml.ac.uk.

ORCID 8

Matthew Cole: 0000-0001-5910-1189

Andy M. Booth: 0000-0002-4702-2210

Notes

The authors declare no competing financial interest.

\section{ACKNOWLEDGMENTS}

Funding was provided by the Natural Environment Research Council (NE/L007010, NE/L002582/1, NE/P006280/1, and NE/L002434/1), the JPI Oceans project "PLASTOX" (direct and indirect ecotoxicological impacts of microplastics on marine organisms; Research Council of Norway, grant no. 257479 ), and the RCN project "MICROFIBRE" (grant no. 268404). Our thanks to Iurgi Salaberria for assistance in planning the studies and providing access to facilities at NTNU.

\section{REFERENCES}

(1) Hartmann, N. B.; Hüffer, T.; Thompson, R.; Hassellöv, M.; Verschoor, A.; Daugaard, A.; Rist, S.; Karlsson, T. M.; Brennholt, N.; Cole, M.; Herrling, M.; Heß, M.; Ivleva, N.; Lusher, A.; Wagner, M. Are we speaking the same language? Recommendations for a definition and categorization framework for plastic debris. Environ. Sci. Technol. 2019, 53, 1039-1047. 
(2) Lusher, A. Microplastics in the marine environment: distribution, interactions and effects. In Marine Anthropogenic Litter; Bergmann, M., Gutow, L., Klages, M., Eds.; Springer: 2015; pp 245-307.

(3) Cole, M.; Lindeque, P.; Halsband, C.; Galloway, T. S. Microplastics as contaminants in the marine environment: A review. Mar. Pollut. Bull. 2011, 62, 2588-2597.

(4) Weinstein, J. E.; Crocker, B. K.; Gray, A. D. From macroplastic to microplastic: Degradation of high-density polyethylene, polypropylene, and polystyrene in a salt marsh habitat. Environ. Toxicol. Chem. 2016, 35 (7), 1632-1640.

(5) Eriksen, M.; Lebreton, L. C.; Carson, H. S.; Thiel, M.; Moore, C. J.; Borerro, J. C.; Galgani, F.; Ryan, P. G.; Reisser, J. Plastic Pollution in the World's Oceans: More than 5 Trillion Plastic Pieces Weighing over 250,000 Tons Afloat at Sea. PLoS One 2014, 9 (12), e111913.

(6) Andrady, A. L. Persistence of plastic litter in the oceans. In Marine Anthropogenic Litter; Bergmann, M., Gutow, L., Klages, M., Eds.; Springer: 2015; pp 57-72.

(7) FAO Microplastics in Fisheries and Aquaculture: Status of Knowledge on Their Occurrence and Implications for Aquatic Organisms and Food Safety; FAO: Rome, Italy, 2017; Vol. 615.

(8) Steer, M.; Cole, M.; Thompson, R. C.; Lindeque, P. K. Microplastic ingestion in fish larvae in the western English Channel. Environ. Pollut. 2017, 226, 250-259.

(9) Catarino, A. I.; Macchia, V.; Sanderson, W. G.; Thompson, R. C.; Henry, T. B. Low levels of microplastics (MP) in wild mussels indicate that MP ingestion by humans is minimal compared to exposure via household fibres fallout during a meal. Environ. Pollut. 2018, 237, 675-684.

(10) Foekema, E. M.; De Gruijter, C.; Mergia, M. T.; van Franeker, J. A.; Murk, A. J.; Koelmans, A. A. Plastic in north sea fish. Environ. Sci. Technol. 2013, 47 (15), 8818-8824.

(11) Lusher, A.; McHugh, M.; Thompson, R. Occurrence of microplastics in the gastrointestinal tract of pelagic and demersal fish from the English Channel. Mar. Pollut. Bull. 2013, 67 (1-2), 94-99.

(12) Duncan, E. M.; Broderick, A. C.; Fuller, W. J.; Galloway, T. S.; Godfrey, M. H.; Hamann, M.; Limpus, C. J.; Lindeque, P. K.; Mayes, A. G.; Omeyer, L. C.; et al. Microplastic ingestion ubiquitous in marine turtles. Global change biology 2019, 25 (2), 744-752.

(13) Nelms, S.; Barnett, J.; Brownlow, A.; Davison, N.; Deaville, R.; Galloway, T.; Lindeque, P.; Santillo, D.; Godley, B. Microplastics in marine mammals stranded around the British coast: ubiquitous but transitory? Sci. Rep. 2019, 9 (1), 1075.

(14) Meeker, J. D.; Sathyanarayana, S.; Swan, S. H. Phthalates and other additives in plastics: human exposure and associated health outcomes. Philos. Trans. R. Soc., B 2009, 364 (1526), 2097-2113.

(15) Johansen, M. P.; Prentice, E.; Cresswell, T.; Howell, N. Initial data on adsorption of $\mathrm{Cs}$ and $\mathrm{Sr}$ to the surfaces of microplastics with biofilm. J. Environ. Radioact. 2018, 190, 130-133.

(16) Zuo, L.-Z.; Li, H.-X.; Lin, L.; Sun, Y.-X.; Diao, Z.-H.; Liu, S.; Zhang, Z.-Y.; Xu, X.-R. Sorption and desorption of phenanthrene on biodegradable poly (butylene adipate co-terephtalate) microplastics. Chemosphere 2019, 215, 25-32.

(17) Muller-Karanassos, C.; Turner, A.; Arundel, W.; Vance, T.; Lindeque, P. K.; Cole, M. Antifouling paint particles in intertidal estuarine sediments from southwest England and their ingestion by the harbour ragworm, Hediste diversicolor. Environ. Pollut. 2019, 249, $163-170$.

(18) Syberg, K.; Nielsen, A.; Khan, F. R.; Banta, G. T.; Palmqvist, A.; Jepsen, P. M. Microplastic potentiates triclosan toxicity to the marine copepod Acartia tonsa (Dana). J. Toxicol. Environ. Health, Part A 2017, 80 (23-24), 1369-1371.

(19) Wright, S.; Rowe, D.; Thompson, R. C.; Galloway, T. S. Microplastic ingestion decreases energy reserves in marine worms. Curr. Biol. 2013, 23 (23), 1031-1033.

(20) Wegner, A.; Besseling, E.; Foekema, E.; Kamermans, P.; Koelmans, A. Effects of nanopolystyrene on the feeding behavior of the blue mussel (Mytilus edulis L.). Environ. Toxicol. Chem. 2012, 31 (11), 2490-2497.
(21) Besseling, E.; Wegner, A.; Foekema, E. M.; van den HeuvelGreve, M. J.; Koelmans, A. A. Effects of Microplastic on Fitness and PCB Bioaccumulation by the Lugworm Arenicola marina (L.). Environ. Sci. Technol. 2013, 47 (1), 593-600.

(22) Cole, M.; Lindeque, P.; Fileman, E.; Halsband, C.; Galloway, T. The impact of polystyrene microplastics on feeding, function and fecundity in the marine copepod Calanus helgolandicus. Environ. Sci. Technol. 2015, 49 (2), 1130-1137.

(23) Sussarellu, R.; Suquet, M.; Thomas, Y.; Lambert, C.; Fabioux, C.; Pernet, M. E. J.; Le Goïc, N.; Quillien, V.; Mingant, C.; Epelboin, Y.; et al. Oyster reproduction is affected by exposure to polystyrene microplastics. Proc. Natl. Acad. Sci. U. S. A. 2016, 113 (9), 24302435.

(24) Cole, M.; Lindeque, P. K.; Fileman, E.; Clark, J.; Lewis, C.; Halsband, C.; Galloway, T. S. Microplastics alter the properties and sinking rates of zooplankton faecal pellets. Environ. Sci. Technol. 2016, 50, 3239-3246.

(25) Galloway, T. S.; Cole, M.; Lewis, C. Interactions of microplastic debris throughout the marine ecosystem. Nature Ecology \& Evolution 2017, 1 (5), s41559.

(26) Irigoien, X.; Harris, R. P.; Verheye, H. M.; Joly, P.; Runge, J.; Starr, M.; Pond, D.; Campbell, R.; Shreeve, R.; Ward, P.; et al. Copepod hatching success in marine ecosystems with high diatom concentrations. Nature 2002, 419 (6905), 387-389.

(27) Cole, M.; Lindeque, P.; Fileman, E.; Halsband, C.; Goodhead, R.; Moger, J.; Galloway, T. S. Microplastic ingestion by zooplankton. Environ. Sci. Technol. 2013, 47 (12), 6646-6655.

(28) Setälä, O.; Fleming-Lehtinen, V.; Lehtiniemi, M. Ingestion and transfer of microplastics in the planktonic food web. Environ. Pollut. 2014, 185, 77-83.

(29) Lee, K.-W.; Shim, W. J.; Kwon, O. Y.; Kang, J.-H. SizeDependent Effects of Micro Polystyrene Particles in the Marine Copepod Tigriopus japonicus. Environ. Sci. Technol. 2013, 47 (19), $11278-11283$.

(30) Vroom, R. J.; Koelmans, A. A.; Besseling, E.; Halsband, C. Aging of microplastics promotes their ingestion by marine zooplankton. Environ. Pollut. 2017, 231, 987-996.

(31) Sun, X.; Li, Q.; Zhu, M.; Liang, J.; Zheng, S.; Zhao, Y. Ingestion of microplastics by natural zooplankton groups in the northern South China Sea. Mar. Pollut. Bull. 2017, 115 (1-2), 217-224.

(32) Desforges, J.-P. W.; Galbraith, M.; Ross, P. S. Ingestion of Microplastics by Zooplankton in the Northeast Pacific Ocean. Arch. Environ. Contam. Toxicol. 2015, 69 (4), 320-330.

(33) Gray, A. D.; Weinstein, J. E. Size-and shape-dependent effects of microplastic particles on adult daggerblade grass shrimp (Palaemonetes pugio). Environ. Toxicol. Chem. 2017, 36 (11), 3074-3080.

(34) Botterell, Z. L.; Beaumont, N.; Dorrington, T.; Steinke, M.; Thompson, R. C.; Lindeque, P. K. Bioavailability and effects of microplastics on marine zooplankton: A review. Environ. Pollut. 2019, 245, 98-110.

(35) Paul-Pont, I.; Tallec, K.; Gonzalez-Fernandez, C.; Lambert, C.; Vincent, D.; Mazurais, D.; Zambonino-Infante, J.-L.; Brotons, G.; Lagarde, F.; Fabioux, C.et al. Constraints and priorities for conducting experimental exposures of marine organisms to microplastics. Front. Mar. Sci. 2018, 5 (252) DOI: 10.3389/fmars.2018.00252.

(36) Melle, W.; Runge, J.; Head, E.; Plourde, S.; Castellani, C.; Licandro, P.; Pierson, J.; Jonasdottir, S.; Johnson, C.; Broms, C.; et al. The North Atlantic Ocean as habitat for Calanus finmarchicus: Environmental factors and life history traits. Prog. Oceanogr. 2014, 129, 244-284.

(37) Pond, D. W. The physical properties of lipids and their role in controlling the distribution of zooplankton in the oceans. J. Plankton Res. 2012, 34 (6), 443-453.

(38) Marker, T.; Andreassen, P.; Arashkewich, E.; Hansen, B. W. Lipid deposition and sexual maturation in cohorts of Calanus finmarchicus (Gunnerus) originating from Bergen $(60 \mathrm{~N})$ and Tromsø $(69 \mathrm{~N})$ reared in Tromsø, Norway. Mar. Biol. 2003, 143 (2), 283-296. 
(39) Lee, R. F.; Hagen, W.; Kattner, G. Lipid storage in marine zooplankton. Mar. Ecol.: Prog. Ser. 2006, 307, 273-306.

(40) Tarrant, A. M.; Baumgartner, M. F.; Hansen, B. H.; Altin, D.; Nordtug, T.; Olsen, A. J. Transcriptional profiling of reproductive development, lipid storage and molting throughout the last juvenile stage of the marine copepod Calanus finmarchicus. Front. Zool. 2014, 11 (1), 91.

(41) Jones, R. H.; Flynn, K. J.; Anderson, T. R. Effect of food quality on carbon and nitrogen growth efficiency in the copepod Acartia tonsa. Mar. Ecol.: Prog. Ser. 2002, 235, 147-156.

(42) Cole, M., Novel method for preparing microplastic fibres. Sci. Rep. 2016 DOI: 10.1038/srep34519.

(43) Frost, B. W. Effect of size and concentration of food particles on the feeding behaviour of the marine planktoinic copepod Calanus pacificus. Limnol. Oceanogr. 1972, 17, 805-815.

(44) Folch, J.; Lees, M.; Sloane Stanley, G. A simple method for the isolation and purification of total lipides from animal tissues. J. Biol. Chem. 1957, 226 (1), 497-509.

(45) R. C. Team. R: A Language and Environment for Statistical Computing; R Foundation for Statistical Computing: Vienna, Austria, 2016.

(46) Meyer-Harms, B.; Irigoien, X.; Head, R.; Harris, R. Selective feeding on natural phytoplankton by Calanus finmarchicus before, during, and after the 1997 spring bloom in the Norwegian Sea. Limnol. Oceanogr. 1999, 44 (1), 154-165.

(47) Leiknes, Ø.; Striberny, A.; Tokle, N. E.; Olsen, Y.; Vadstein, O.; Sommer, U. Feeding selectivity of Calanus finmarchicus in the Trondheimsfjord. J. Sea Res. 2014, 85, 292-299.

(48) Meyer, B.; Irigoien, X.; Graeve, M.; Head, R.; Harris, R. Feeding rates and selectivity among nauplii, copepodites and adult females of Calanus finmarchicus and Calanus helgolandicus. Helgoland Marine Research 2002, 56 (3), 169-176.

(49) Marshall, S.; Orr, A. On the biology of Calanus finmarchicus VIII. Food uptake, assimilation and excretion in adult and stage V Calanus. J. Mar. Biol. Assoc. U. K. 1955, 34 (3), 495-529.

(50) Jemec, A.; Horvat, P.; Kunej, U.; Bele, M.; Kržan, A. Uptake and effects of microplastic textile fibers on freshwater crustacean Daphnia magna. Environ. Pollut. 2016, 219, 201-209.

(51) Bakir, A.; Rowland, S. J.; Thompson, R. C. Enhanced desorption of persistent organic pollutants from microplastics under simulated physiological conditions. Environ. Pollut. 2014, 185, 16-23.

(52) Litchman, E.; Ohman, M. D.; Kiørboe, T. Trait-based approaches to zooplankton communities. J. Plankton Res. 2013, 35 (3), 473-484.

(53) Blarer, P.; Burkhardt-Holm, P. Microplastics affect assimilation efficiency in the freshwater amphipod Gammarus fossarum. Environ. Sci. Pollut. Res. 2016, 23 (23), 23522-23532.

(54) Jónasdóttir, S. H. Lipid content of Calanus finmarchicus during overwintering in the Faroe-Shetland Channel. Fisheries Oceanography 1999, 8, 61-72.

(55) Häfker, N. S.; Teschke, M.; Last, K. S.; Pond, D. W.; Hüppe, L.; Meyer, B. Calanus finmarchicus seasonal cycle and diapause in relation to gene expression, physiology, and endogenous clocks. Limnol. Oceanogr. 2018, 63 (6), 2815-2838.

(56) Crain, J. A.; Miller, C. B. Effects of starvation on intermolt development in Calanus finmarchicus copepodites: a comparison between theoretical models and field studies. Deep Sea Res., Part II 2001, 48 (1-3), 551-566.

(57) Rodríguez, E. M.; Medesani, D. A.; Fingerman, M. Endocrine disruption in crustaceans due to pollutants: a review. Comp. Biochem. Physiol., Part A: Mol. Integr. Physiol. 2007, 146 (4), 661-671.

(58) Andersen, H. R.; Wollenberger, L.; Halling-Sørensen, B.; Kusk, K. O. Development of copepod nauplii to copepodites-a parameter for chronic toxicity including endocrine disruption. Environ. Toxicol. Chem. 2001, 20 (12), 2821-2829.

(59) Waddy, S.; Burridge, L.; Hamilton, M.; Mercer, S.; Aiken, D.; Haya, K. Rapid communication/communication rapide emamectin benzoate induces molting in American lobster, Homarus americanus. Can. J. Fish. Aquat. Sci. 2002, 59 (7), 1096-1099.
(60) Guyon, A.; Smith, K. F.; Charry, M. P.; Champeau, O.; Tremblay, L. A. Effects of chronic exposure to benzophenone and diclofenac on DNA methylation levels and reproductive success in a marine copepod. J. Xenobiot. 2018, 8 (1), 7674.

(61) Jarry, H.; Christoffel, J.; Rimoldi, G.; Koch, L.; Wuttke, W. Multi-organic endocrine disrupting activity of the UV screen benzophenone 2 (BP2) in ovariectomized adult rats after 5 days treatment. Toxicology 2004, 205 (1-2), 87-93.

(62) Kim, S.; Jung, D.; Kho, Y.; Choi, K. Effects of benzophenone-3 exposure on endocrine disruption and reproduction of Japanese medaka (Oryzias latipes) - A two generation exposure study. Aquat. Toxicol. 2014, 155, 244-252.

(63) Kinnberg, K. L.; Petersen, G. I.; Albrektsen, M.; Minghlani, M.; Awad, S. M.; Holbech, B. F.; Green, J. W.; Bjerregaard, P.; Holbech, $\mathrm{H}$. Endocrine-disrupting effect of the ultraviolet filter benzophenone-3 in zebrafish, Danio rerio. Environ. Toxicol. Chem. 2015, 34 (12), 2833-2840.

(64) Rochman, C. M.; Brookson, C.; Bikker, J.; Djuric, N.; Earn, A.; Bucci, K.; Athey, S.; Huntington, A.; Mcllwraith, H.; Munno, K.; et al. Rethinking microplastics as a diverse contaminant suite. Environ. Toxicol. Chem. 2019, 38 (4), 703-711.

(65) de Sá, L. C.; Oliveira, M.; Ribeiro, F.; Rocha, T. L.; Futter, M. N. Studies of the effects of microplastics on aquatic organisms: What do we know and where should we focus our efforts in the future? Sci. Total Environ. 2018, 645, 1029-1039.

(66) Lusher, A.; Welden, N.; Sobral, P.; Cole, M. Sampling, isolating and identifying microplastics ingested by fish and invertebrates. Anal. Methods 2017, 9, 1346-1360.

(67) Erni-Cassola, G.; Zadjelovic, V.; Gibson, M. I.; Christie-Oleza, J. A. Distribution of plastic polymer types in the marine environment; A meta-analysis. J. Hazard. Mater. 2019, 369, 691-698.

(68) Enders, K.; Lenz, R.; Stedmon, C. A.; Nielsen, T. G. Abundance, size and polymer composition of marine microplastics $\geq$ $10 \mu \mathrm{m}$ in the Atlantic Ocean and their modelled vertical distribution. Mar. Pollut. Bull. 2015, 100 (1), 70-81.

(69) Huvet, A.; Paul-Pont, I.; Fabioux, C.; Lambert, C.; Suquet, M.; Thomas, Y.; Robbens, J.; Soudant, P.; Sussarellu, R. Reply to Lenz et al.: Quantifying the smallest microplastics is the challenge for a comprehensive view of their environmental impacts. Proc. Natl. Acad. Sci. U. S. A. 2016, 113 (29), E4123-E4124. 